\title{
Long-Term Effects of Neonatal Treatment With Dexamethasone, L-Carnitine, and Combinations Thereof in Rats
}

\author{
YAN LIU, AND FEIKE R. VAN DER LEIJ \\ Department of Endocrinology [Y.L.], the Third Hospital of Hebei Medical University, Shijiazhuang, Hebei 050051, China; Unit Life \\ Sciences and Technology [F.R.L.], University of Applied Sciences, Van Hall Larenstein and NHL Hogeschool, Leeuwarden 8901BV, \\ The Netherlands
}

\begin{abstract}
Because L-carnitine (L-CAR) is a potential substitute for neonatal dexamethasone (DEX) with respect to the prevention of long-term side effects, rats were treated on d 1, 2, and 3 after birth with saline, DEX, L-CAR, half the dose of DEX, and L-CAR + half DEX. DEX led to growth retardation, increased mortality, and severe kidney damage at $50 \mathrm{wk}$ of age. L-CAR had no negative effects on growth, kidney function at $50 \mathrm{wk}$, and survival at $101 \mathrm{wk}$. Growth retardation was induced transiently by half DEX and permanently by L-CAR + half DEX, slightly reduced kidney function but no reduced life span was found in both these groups. Except for the DEX group, blood glucose levels were normal at $50 \mathrm{wk}$ in all groups. A serendipitous finding was that L-CAR treatment caused one-third less food intake; however, these rats maintained normal body weight. In conclusion, L-CAR, a lower dose of DEX, and their combination caused less negative effects in later life. Because L-CAR + half DEX had a negative effect on growth, attention to monitor L-CAR levels during DEX treatment of preterm newborns seems to be justified. The finding that neonatal L-CAR caused reduced food intake in later life warrants further investigation. (Pediatr Res 69: 148-153, 2011)
\end{abstract}

$\mathrm{G}$ lucocorticoids (GCs) such as dexamethasone (DEX) are frequently used to prevent chronic lung disease in preterm newborns because of their anti-inflammatory action $(1,2)$. However, accumulated data indicate the occurrence of undesired side effects of neonatal DEX treatment (3-8). These long-term effects include growth retardation, hypertension, cardiopathy, hyperglycemia, and insulin resistance. Evidence suggests a crucial role for renal dysfunction as a progressive pathology (9). Indeed, neonatal DEX in experimental studies leads to increased mortality $(9-11)$. Although the translation of experimental rat studies to the human situation may be less alarming than previously thought, alternative treatments, which are also effective but less harmful, are highly advocated. Therefore, an established rat model of neonatal DEX treatment is the model of choice to test potential nonsteroid substitutes for DEX.

L-Carnitine [L-CAR; IUPAC name (3R)-3-hydroxy-4trimethylazaniumylbutanoate; also referred to as L-CAR in this study] might be a potentially promising (partial) substitute for DEX (12-15). L-CAR is both an endogenous compound

Received August 5, 2010; accepted September 30, 2010.

Correspondence: Feike R. van der Leij, Ph.D., Unit Life Sciences and Technology, Agora 1, Van Hall Larenstein Building, Postbus 1528, 8901BV Leeuwarden, The Netherlands; e-mail: feike.vanderleij@wur.nl

Supported by the Groningen University Institute for Drug Exploration, The Netherlands Heart Foundation, and Sigma-Tau/Ethifarma, The Netherlands. and an important nutrient with several roles in energy homeostasis (16). Its importance for the mediation of long-chain fatty acid transport across mitochondrial membranes, facilitating energy production from fatty acid oxidation, is well known. Moreover, its role as energy-independent substitute for CoA in the buffering of acetyl-CoA pools in peroxisomes, mitochondria, and the cytosolic compartment of the cell is appreciated $(16,17)$, in addition to its function as potential osmolyte (18). Clinical and experimental work in the $1980 \mathrm{~s}$ and 1990s by Lohninger et al. (12-15) pointed to the potential of L-CAR as partial substitute for GCs when used in combination with betamethasone. However, that particular approach aimed at prenatal maternal administration and has not been widely adapted. Prenatal DEX treatments are not known to cause negative side effects to the extent known for neonatal DEX treatments.

In recent years, evidence emerged that L-CAR at high doses may mimic some biological activities of GCs, including the suppression of immunoreactions in a GC-like fashion, and the activation of GC-receptor- $\alpha$ and other GC-responsive genes (19-21). The transactivation of GC-responsive promoters by L-CAR seems similar to the transactivation by DEX as this effect can be suppressed by RU486, a known competitive inhibitor of GCs $(20,22)$. Furthermore, L-CAR exerts competitive inhibition on the binding of DEX to the GC-receptor- $\alpha$ in HeLa cells $(20,22)$. These data suggest that L-CAR potentially shares some of the biological and therapeutic properties of GCs and exerts GC-like immunomodulatory effects.

It has been identified in rats that maternal administration with L-CAR or L-CAR-betamethasone combinations can significantly increase the surfactant content of fetal rat lungs $(18,23)$. Therefore, L-CAR or its combination with lower doses of GCs might be a possible substitute for GCs. In human studies, the first clinical report in 1983 showed that maternal L-CAR-betamethasone combinations can stimulate lung maturation and reduce the incidence of respiratory dysfunction in newborns (15). Although all these studies were performed prenatally, it may well be possible that neonatal L-CAR or its combination with GCs is also effective. Therefore, the question that needs to be addressed first is whether neonatal administration of L-CAR or L-CAR-GC combinations leads to Abbreviations: L-CAR, L-carnitine; DEX, dexamethasone; GCs, glucocor-
ticoids; SAL, saline 
similar negative effects in later life as GCs do. In a previous study in rats (9), we found that neonatal DEX administration causes severe renal damage, which in turn might be the major cause for reduced life span. Hence, the measurement of renal function in combination with body-weight analysis and the determination of survival rates are the first methods of choice to assess the potential value of L-CAR as a possible (partial) substitute for DEX with respect to the long-term effects in vivo.

\section{METHODS}

Animals. Pregnant Wistar rats (270-300 g) were housed individually and kept under conventional housing conditions with free access to food and water. Pups were born on d 21-22 of gestation. On the day of birth (d 0), male pups were selected and randomly divided into treatment and control groups. Pups were housed in groups of six per cage with a randomly assigned mother. The mothers were removed after $3 \mathrm{wk}$, and the rats were housed in groups of three per cage. Temperature and humidity were kept constant, and the rats had

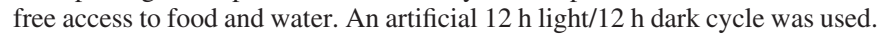

Male rat pups were treated i.p. at d 1,2, and 3 after birth with tapering doses of L-CAR (L-CAR, 100, 60, and $20 \mu \mathrm{g} / \mathrm{g}$; body weight, $n=22$ ); DEX (DEX, 0.5, 0.3, and $0.1 \mu \mathrm{g} / \mathrm{g} ; n=30) ; 1 / 2 \operatorname{dose}$ DEX (1/2DEX, 0.25, 0.15, and $0.05 \mu \mathrm{g} / \mathrm{g} ; n=20)$; and L-CAR $+1 / 2 \operatorname{DEX}(100+0.25 \mu \mathrm{g} / \mathrm{g}, 60+0.15 \mu \mathrm{g} / \mathrm{g}$, and $20+0.05 \mu \mathrm{g} / \mathrm{g} ; n=18)$. Controls were injected with equal volumes (10 $\mu \mathrm{L} / \mathrm{g}$ ) of sterile pyrogen-free saline (SAL; $n=22$ ). Full DEX treatment was done as described earlier $(7-11,24)$, and L-CAR was obtained from Sigma Chemical Co.-Aldrich (Catalog nr. C0158).

Body weight was measured weekly. Rats were terminated at 101 wk of age except the DEX-treated rats, which were terminated at $50 \mathrm{wk}$. The latter group has been analyzed in depth for several parameters on cardiac, hepatic, and renal performance as reported before $(9,11,24)$. All experiments were approved by the University of Groningen Ethical Committee on Animal Experiments.

Metabolic cage methods. At $50 \mathrm{wk}$ of age, $24 \mathrm{~h}$ urine was collected in a metabolic cage ( $n=8-9$ /group). Urine protein, urine creatinine, and serum creatinine concentrations were measured in an auto analyzer (Merck Mega, Darmstadt, Germany). Creatinine clearance was calculated by the following formula:

$$
\text { Creatinine clearance }(\mathrm{mL} / \mathrm{min})=(\mathrm{uCr} \times \mathrm{uV}) /(\mathrm{sCr} \times 1440)
$$

where $\mathrm{uCr}$ is the urine creatinine concentration in $\mathrm{mmol} / \mathrm{L} ; \mathrm{uV}$ is the $24 \mathrm{~h}$ urine volume in $\mathrm{mL}$; and $\mathrm{sCr}$ is the serum creatinine concentration in $\mu \mathrm{mol} / \mathrm{L}$.

Blood samples were collected from the abdominal artery under anesthesia. Blood glucose was measured by a Medisense Precision glucose meter (Abbott, Amersfoort, The Netherlands).

Statistics. Survival analysis was investigated by the Kaplan-Meier method, and the differences between groups were examined by the log-rank test. One-way ANOVA was used to assess differences in body weights, and $p<$ 0.05 was considered significant. Analyses were performed by using SPSS for Windows software (SPSS, Chicago, IL).

\section{RESULTS}

In this study, we compared the long-term effects of five different treatments that were given to neonatal rats on $\mathrm{d} 1,2$, and 3 after birth. The five groups were SAL (control), L-CAR, $1 / 2$ DEX, L-CAR $+1 / 2$ DEX, and full DEX. We compared the effects of the treatment regimes on growth, survival, and renal function. In addition, we measured food and water intake and blood glucose levels.

Effect of the treatments on growth. Compared with the SAL-treated group, L-CAR did not have any effects on the growth. The $1 / 2 \mathrm{DEX}$ group showed a transiently impaired body weight gain in the first $5 \mathrm{wk}$ of life and then the body weight caught up till normal levels. The $\mathrm{L}-\mathrm{CAR}+1 / 2 \mathrm{DEX}$ and DEX had comparable effects on growth retardation, which caused significantly impaired growth compared with the SAL group, and this was even significant when compared with the $1 / 2$ DEX group in the first $5 \mathrm{wk}$ of life, indicating that $\mathrm{L}-\mathrm{CAR}$

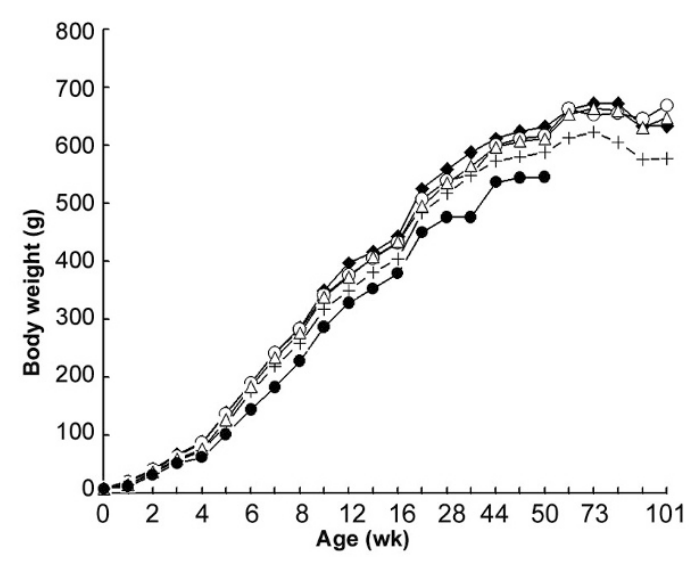

Figure 1. Body weight gain of rats under different treatments. Compared with the SAL group, L-CAR did not have any effect on growth. The $1 / 2$ DEX group showed a transiently impaired body weight gain in the first $5 \mathrm{wk}$ of life and then caught up to normal levels. The L-CAR $+1 / 2$ DEX and full DEX had comparable effects and caused significantly impaired growth compared with SAL, and this was even significant compared with $1 / 2$ DEX in the first 5 wk of life, indicating that L-CAR exerts a synergistic effect on growth with lower doses of DEX. Data are presented as mean. Symbols (group sizes): $\downarrow$, SAL $(n=22) ; \bigcirc, \mathrm{L}-\mathrm{CAR}(n=22) ; \triangle, 1 / 2 \mathrm{DEX}(n=20) ;+, \mathrm{L}-\mathrm{CAR}+1 / 2 \mathrm{DEX}(n=$ $18)$; and $\operatorname{DEX}(n=30)$.

exerted a synergistic effect with lower doses of DEX on growth retardation (Figs. 1 and $2 A$ ).

Effect of the treatments on survival. As reported previously (9-11), neonatal DEX leads to significantly increased mortality before $50 \mathrm{wk}$ of age compared with SAL-treated controls. In this study, compared with SAL-treated animals, there were no reduced life spans found for L-CAR, L-CAR $+1 / 2$ DEX, and $1 / 2$ DEX till $101 \mathrm{wk}$ of age. There were also no differences between those groups, indicating that till the age of investigation no increased mortality occurred (Table 1). Because the animals suffered from old-age complications, the experiment was stopped after 101 wk.

Water and food intake and blood glucose levels in 50-wkold rats. Compared with SAL controls, DEX administration in neonatal rats caused normal $24 \mathrm{~h}$ food intake and significantly increased water consumption; the latter increase might be due to increased urine volume, the consequence of impaired renal function. Intriguingly, L-CAR treatment leads to significantly reduced $24 \mathrm{~h}$ water and food intake compared with SAL treatment (Fig. $2 B$ and $D$ ). Significantly reduced 24-h food consumption was also noted in L-CAR $+1 / 2$ DEX-treated animals (Fig. 2D), indicating that neonatal treatment of L-CAR may have some effects on appetite in rats at $50 \mathrm{wk}$ of age. Both $1 / 2 \mathrm{DEX}$ and $\mathrm{L}-\mathrm{CAR}+1 / 2 \mathrm{DEX}$-treated rats tended to have more water intake, but these differences did not reach statistical significance (Fig. 2B).

DEX-treated rats had significantly lower blood glucose when compared with SAL and also when compared with other groups separately. No differences are found in blood glucose levels in animals treated with L-CAR, 1/2DEX, and L-CAR + $1 / 2$ DEX (Fig. 2C).

Effect of the treatments on renal function in 50-wk-old rats. The parameters of renal function of DEX-treated rats have been described in our previous study (9), which indicated 

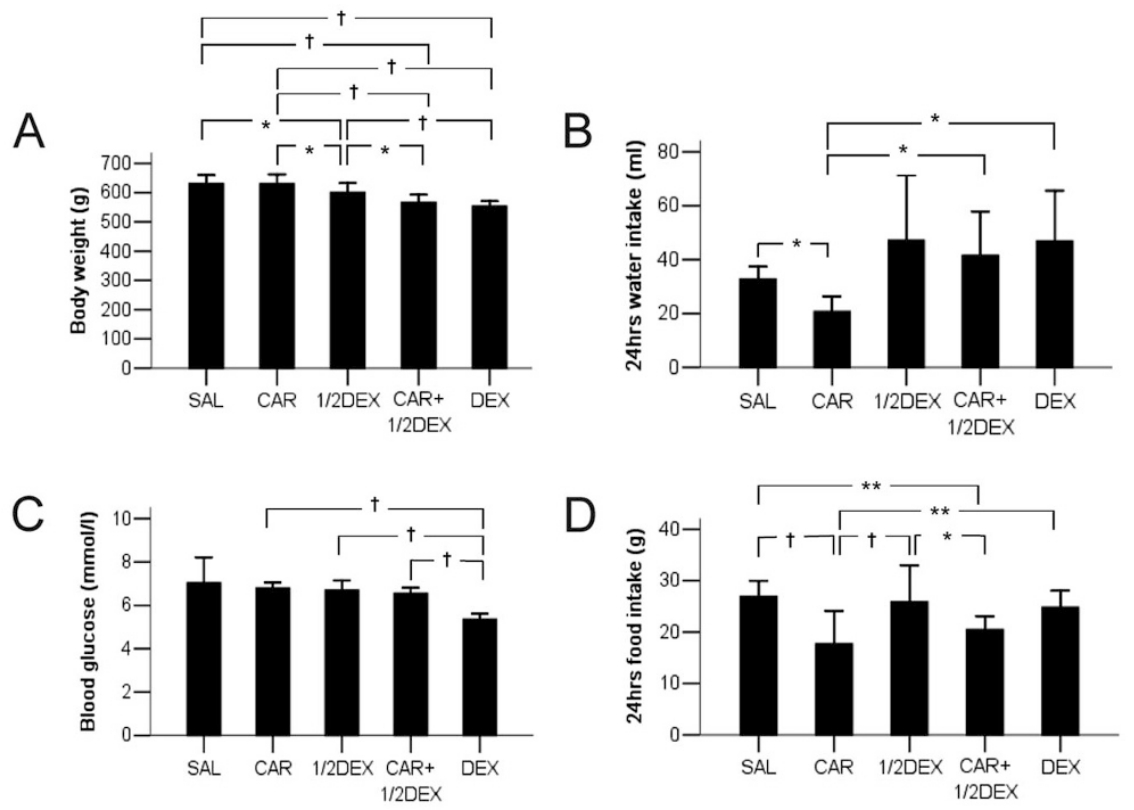

Figure 2. Body weight, $24 \mathrm{~h}$ water and food intake, and blood glucose levels. (A) $1 / 2 \mathrm{DEX}$, L-CAR + 1/2DEX, and DEX caused reduced body weight compared with SAL. (B) Compared with SAL, and also with L-CAR $+1 / 2$ DEX and with DEX, L-CAR treatment led to significantly reduced $24 \mathrm{~h}$ water intake. (C) DEX-treated rats showed significantly lower blood glucose levels compared with other groups separately. No differences in blood glucose were found in animals treated with L-CAR, 1/2DEX, and L-CAR + $1 / 2$ DEX. (D) Rats with L-CAR or L-CAR + $1 / 2$ DEX treatment showed significantly reduced $24 \mathrm{~h}$ food intake. Data are expressed as mean \pm SD, $(n=8-9$ per group). $* p<0.05, * * p<$ 0.01 , and $\dagger p<0.005$. Differences were calculated by one-way ANOVA.
Table 1. Percentage of survival of neonatally treated rats at different ages

\begin{tabular}{cccccc}
\hline & \multicolumn{5}{c}{ L -CAR +} \\
Weeks & SAL & L -CAR & $1 / 2$ DEX & $1 / 2$ DEX & Full DEX* \\
\hline 28 & 100 & 100 & 100 & 100 & 97 \\
32 & 100 & 100 & 100 & 100 & 93 \\
36 & 100 & 100 & 100 & 100 & 86 \\
40 & 100 & 100 & 100 & 100 & 86 \\
44 & 100 & 100 & 100 & 95 & 86 \\
48 & 100 & 100 & 100 & 95 & 79 \\
68 & 100 & 95 & 94 & 95 & \\
72 & 100 & 91 & 89 & 95 & \\
76 & 100 & 91 & 89 & 85 & \\
80 & 100 & 86 & 89 & 80 & \\
84 & 86 & 86 & 83 & 80 & \\
88 & 86 & 82 & 78 & 70 & \\
92 & 73 & 82 & 67 & 60 & \\
96 & 45 & 73 & 67 & 50 & \\
100 & 37 & 73 & 33 & 33 & \\
\hline
\end{tabular}

* The full DEX group was terminated at wk 50. Significant shorter life span of this group was demonstrated previously (9). There were no significant differences between the other groups.

that DEX administration led to increased urine volume, urinary protein content, and a decreased creatinine clearance ratio. In this experiment, compared with SAL-treated animals, L-CAR administration in neonatal rats had no effect on 24-h urine volume at $50 \mathrm{wk}$ of age, and $1 / 2 \mathrm{DEX}$ or L-CAR $+1 / 2 \mathrm{DEX}$ treatment tended to increase 24-h urine volume without reaching statistical significance (Fig. $3 A$ ).

Urinary protein/creatinine ratio is a sensitive marker for proteinuria. Although L-CAR, 1/2DEX, and L-CAR $+1 / 2$ DEX treatments did not have any effect on total protein content in $24 \mathrm{~h}$ urine compared with the SAL group (Fig. 3B), both $1 / 2$ DEX and $\mathrm{L}-\mathrm{CAR}+1 / 2 \mathrm{DEX}$ led to increased urinary protein/ creatinine ratio while statistical difference was only found for $\mathrm{L}-\mathrm{CAR}+1 / 2 \mathrm{DEX}$. There was no difference in this ratio in rats treated with L-CAR in comparison with SAL (Fig. 3C).
Compared with SAL-treated rats, L-CAR treatment did not cause any effect on the creatinine clearance, which is the crucial parameter of renal filter function. Both $1 / 2 \mathrm{DEX}$ and $\mathrm{L}-\mathrm{CAR}+1 / 2 \mathrm{DEX}$ rats showed significantly reduced creatinine clearance, indicating impaired renal function at $50 \mathrm{wk}$. In addition, this parameter was even lower in the DEX group when compared with the $1 / 2$ DEX group (Fig. $3 D$ ).

\section{DISCUSSION}

In this study, we evaluated the potential of L-CAR as a complete or partial substitute for the treatment by GCs with respect to undesired side effects later in life in a rat model. The data suggest that from the long-term point of view, L-CAR has no negative effects on growth and renal functions, whereas L-CAR has a synergistic effect with $1 / 2$ DEX on growth retardation. Both L-CAR $+1 / 2$ DEX and $1 / 2$ DEX alone caused impaired renal function at $50 \mathrm{wk}$ of age.

Growth retardation is one of the important negative effects of GC administration that is widely seen in animal experiments $(9-11,25,26)$ and may be due to the impaired action of growth hormone and IGF $(25,26)$. In this experiment, we found that a high dose of L-CAR alone had no negative effects on the body weight gain during the experiment. This result is consistent with previous data that maternal L-CAR administration in pigs had no effect on fetal growth and body weight and also caused no differences in IGF and its binding protein mRNA abundance in liver, muscle, and embryonic myoblasts (25).

In this study, we found that $1 / 2$ DEX had a reversible effect on growth in the first $5 \mathrm{wk}$ of life after which the rats caught up to gain weight similar to the SAL- and L-CAR-treatment groups. However, L-CAR $+1 / 2$ DEX and full DEX had comparable persistent effects on body weight gain impairment. This phenomenon has two implications. First, L-CAR together with a lower dose of DEX exerts a synergistic effect on growth. Second, the reversibility of growth suppression by a lower dose of DEX is changed to irreversible suppression 

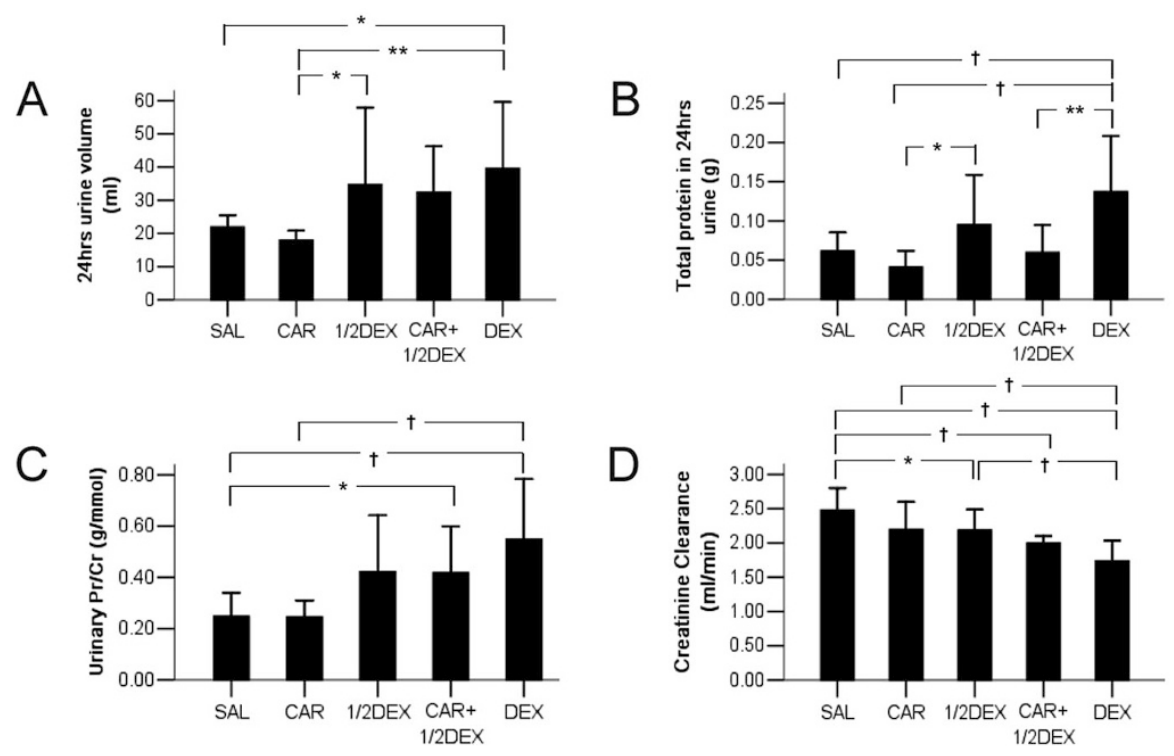

Figure 3. Renal function parameters. (A) At $50 \mathrm{wk}$ of age, the DEX group showed significantly increased $24 \mathrm{~h}$ urine volume compared with SAL and L-CAR, but $1 / 2$ DEX and L-CAR $+1 / 2$ DEX showed no statistical differences compared with SAL. $(B)$ Compared with SAL-treatment, L-CAR, 1/2DEX, and L-CAR $+1 / 2$ DEX treatments did not affect total protein content in $24 \mathrm{~h}$ urine, except DEX-treatment, which caused significantly elevated protein contents. (C) L-CAR had no effect on urinary protein/creatinine $(\mathrm{Pr} / \mathrm{Cr})$ ratio compared with SAL. Significant differences were only found for L-CAR $+1 / 2 \mathrm{DEX}$ and DEX compared with SAL. $(D)$ Compared with SAL, L-CAR did not cause any effect on the creatinine clearance ratio. 1/2DEX, L-CAR + 1/2DEX, and DEX caused significantly reduced creatinine clearance, indicating impaired renal function at $50 \mathrm{wk}$ of age. This parameter is even lower in the DEX group compared with the $1 / 2 \mathrm{DEX}$ group. Data are expressed as mean $\pm \mathrm{SD},\left(n=8-9\right.$ per group). ${ }^{*} p<0.05, * * p<$ 0.01 , and $\dagger p<0.005$. Differences were calculated by one-way ANOVA. when L-CAR is given together with the lower dose of DEX. Without L-CAR, this phenomenon simply seems to be GC dose dependent: a lower dose of GCs leads to reversible growth retardation, whereas the full dose leads to pertinent growth retardation. Given these observations, attention to monitor L-CAR levels during DEX treatment of preterm newborns seems to be justified. However, given that neonatal rodents might have more reduced functional hypothalamicpituitary-adrenal and adipoinsular axes on DEX treatment than human babies (27), it might be reasonable that rats are more susceptible than humans to permanent growth retardation caused by large doses of GCs.

With regard to survival, it has earlier been reported that neonatal DEX administration leads to increased mortality in rats $(9-11)$. It is clear that neonatal full DEX treatment leads to significantly increased mortality already before $50 \mathrm{wk}$, and the kidney damage presumably is the main cause of death and reduced life span. This alarming observation is completely absent in the L-CAR, L-CAR + 1/2DEX, and $1 / 2 \mathrm{DEX}$ groups, supporting the idea to further investigate the potentials of L-CAR as partial substitute for DEX or other GCs. Apart from this important notice, our survival analysis yielded more information. First, L-CAR-treated rats tended to live longer than SAL-treated animals although there was no statistical significance $(p=0.075)$. This tendency was also found in the median survival time, which indicated that L-CAR treatment led to higher median survival time than SAL treatment (data not shown). The observed tendency is in line with earlier observations of the effect of (acetyl-) L-CAR on the longevity in old rats (28) and animal models of Alzheimer's disease (29) and amylotrophic lateral sclerosis (30). Second, compared with SAL, there were no differences in survival in L-CAR + $1 / 2 \mathrm{DEX}$ and $1 / 2 \mathrm{DEX}$ rats, neither was there a difference between the latter two groups. This indicates that from the long-term point of view, lower doses of DEX do not lead to higher mortality, and this effect is not synergistically worsened by L-CAR supplementation. Therefore, L-CAR supple- mentation might improve the survival in general; however, more studies need to be done to justify firm conclusions on this matter.

With respect to kidney function, endogenous GCs play important roles in the renal development and maturation. High doses of exogenous GCs are known to result in kidney damage (31-33). Animal offspring after maternal DEX treatment had lower body- and kidney weight and less nephrons (34,35), which points at inhibited cell proliferation and disrupted nephrogenesis. Our previous study showed that a rebound inflammatory response after DEX treatment might be the main cause that triggers the fibrotic process (9). We assume that DEX administration might cause renal injury in the tubular system at early age, and a disturbed renin-angiotensin system might be involved (36).

In this study, we have investigated kidney function by measuring creatinine clearance and urine protein levels. Creatinine clearance is commonly used to predict kidney function, especially its filter function. Full DEX led to significantly increased urine protein content and reduced creatinine clearance. These results have been further confirmed by histological examinations, showing that $100 \%$ of the 50 -wk-old rats ended up with kidney disease after full DEX treatment (9). The L-CAR-treated rats tended to have decreased creatinine clearance compared with the SAL group ( $p=0.06)$; however, if we also take parameters such as urine volume, urine protein content, and blood creatinine concentration into account, it seems that L-CAR had no negative effect on kidney function at $50 \mathrm{wk}$. Further evidence revealed that no apparent macromorphological renal damage was found in these rats even at 101 wk of age (data not shown). Thus, although large doses of L-CAR can mimic some GC effects, it had no negative effect on kidney function in later life in this study. Instead, data from recent years have shown that L-CAR might be protective by ameliorating renal injury induced by cisplatin (37) or gentamicin (38). In those studies, L-CAR is thought to prevent the severity of renal cortical proximal tubular necrosis and to 
inhibit mitochondrial dysfunction, DNA injury, lipid peroxidation, and apoptosis of epithelial cells in the kidney $(37,38)$.

The kidney function of rats treated with $\mathrm{L}-\mathrm{CAR}+1 / 2 \mathrm{DEX}$ and $1 / 2$ DEX alone is also noteworthy. Both these groups had significantly reduced creatinine clearance compared with the SAL-treated controls. This, combined with slightly increased urine volume, serum creatinine, and urine protein content, suggests that there might be some, but not severe, impaired kidney function. Moreover, kidney function in L-CAR + $1 / 2 \mathrm{DEX}$ rats was not worse than in $1 / 2 \mathrm{DEX}$ rats and still better than the kidney function after full DEX treatment. The latter is significantly worse than all other treatment regimes, as shown in this study, a previous one (9), which was recently confirmed (39). Thus, neonatal DEX treatment in rats leads to kidney damage in later life, and this effect is dose dependent, i.e. large dose DEX administrations in neonatal rats leads to renal failure at $\sim 50 \mathrm{wk}$, and, lower dose of DEX impairs kidney function less severely and is not life threatening. However, why the effects of a lower dose of DEX on kidney function are not synergistically enhanced by L-CAR supplementation as they have done in lung maturation and growth retardation is still an interesting question that may be further explored. We assume that different GC-receptor levels in different organs at early ages play a role. Because the role of L-CAR as an accelerator of lung maturation is almost exclusively investigated in antenatal treatment, our data may provide a basis for future experiments to test neonatal $L-C A R$ and L-CAR-GC combinations for reduction of bronchopulmonary dysplasia.

Finally, the consequences on food intake by neonatal L-CAR treatment are striking: $24 \mathrm{~h}$ food intake was $<2 / 3(65.7 \%)$ of the intake by controls. The L-CAR group also showed the lowest water intake and urine production of all groups tested. The reduced appetite observed at $50 \mathrm{wk}$ is apparently fully compensated by an increased anabolic rate or nutrient expenditure efficacy, because body weight was normal $(100 \%)$ throughout the experiment. In the light of recent discoveries of presumed carnitine transferase involvements in appetite control (40-43), this observation warrants further investigation.

In conclusion, neonatal administration with $\mathrm{L}-\mathrm{CAR}$, half the dose of DEX, and their combination led to less negative effects in later life than full DEX treatment in rats. However, because L-CAR together with half the dose of DEX had a negative effect on growth, attention to monitor L-CAR levels during DEX treatment of preterm newborns seems to be justified. The unexpected finding that neonatal L-CAR treatment causes reduced food intake in later life warrants further investigation.

Acknowledgments. We thank Professor Folkert Kuipers for facilitating the experiments at the Department of Pediatrics, University Medical Center Groningen, Groningen, The Netherlands.

\section{REFERENCES}

1. Mammel MC, Green TP, Johnson DE, Thompson TR 1983 Controlled trial of dexamethasone therapy in infants with bronchopulmonary dysplasia. Lancet $1: 1356-1358$
2. Avery GB, Fletcher AB, Kaplan M, Brudno DS 1985 Controlled trial of dexamethasone in respirator-dependent infants with bronchopulmonary dysplasia. Pediatrics 75:106-111

3. Smets K, Vanhaesebrouck P 1996 Dexamethasone associated systemic hypertension in low birth weight babies with chronic lung disease. Eur J Pediatr 155:573-575

4. Evans N 1994 Cardiovascular effects of dexamethasone in the preterm infant. Arch Dis Child Fetal Neonatal Ed 70:F25-F30

5. van der Heide-Jalving M, Kamphuis PJ, van der Laan MJ, Bakker JM, Wiegant VM, Heijnen CJ, Veen S, van Bel F 2003 Short- and long-term effects of neonatal glucocorticoid therapy: is hydrocortisone an alternative to dexamethasone? Acta Paediatr 92:827-835

6. Yeh TF, Lin YJ, Lin HC, Huang CC, Hsieh WS, Lin CH, Tsai CH 2004 Outcomes at school age after postnatal dexamethasone therapy for lung disease of prematurity. N Engl J Med 350:1304-1313

7. de Vries WB, van der Leij FR, Bakker JM, Kamphuis PJ, van Oosterhout MF, Schipper ME, Smid GB, Bartelds B, van Bel F 2002 Alterations in adult rat heart after neonatal dexamethasone therapy. Pediatr Res 52:900-906

8. Bal MP, de Vries WB, van der Leij FR, van Oosterhout MF, Berger RM, Baan J, van der Wall EE, van Bel F, Steendijk P 2005 Neonatal glucocorticosteroid treatment causes systolic dysfunction and compensatory dilation in early life: studies in 4-week-old prepubertal rats. Pediatr Res 58:46-52

9. Liu Y, van Goor H, Havinga R, Baller JF, Bloks VW, van der Leij FR, Sauer PJ, Kuipers F, Navis G, de Borst MH 2008 Neonatal dexamethasone administration causes progressive renal damage due to induction of an early inflammatory response. Am J Physiol Renal Physiol 294:F768-F776

10. Kamphuis PJ, de Vries WB, Bakker JM, Kavelaars A, van Dijk JE, Schipper ME, van Oosterhout MF, Croiset G, Heijnen CJ, van Bel F, Wiegant VM 2007 Reduced life expectancy in rats after neonatal dexamethasone treatment. Pediatr Res 61:72-76

11. Liu Y, Havinga R, Bloks VW, Baller JF, van der Leij FR, Reijngoud DJ, Sauer PJ, Kuipers F 2007 Postnatal treatment with dexamethasone perturbs hepatic and cardiac energy metabolism and is associated with a sustained atherogenic plasma lipid profile in suckling rats. Pediatr Res 61:165-170

12. Salzer H, Husslein $P$, Lohninger A, Binstorfer E, Langer M, Schonbauer M, Wagner G, Simbruner G, Popow C 1983 [1st report: alternatives to cortisone therapy. 1st clinical experiences with a L-carnitine-betamethasone combination for the stimulation of fetal lung maturity]. Wien Klin Wochenschr 95:724-728

13. Kurz C, Arbeiter K, Obermair A, Salzer H, Salzer HR, Lohninger A 1993 [Lcarnitine-betamethasone combination therapy versus betamethasone therapy alone in prevention of respiratory distress syndrome]. Z Geburtshilfe Perinatol 197:215-219

14. Lohninger A, Auer B, Lechner S, Salzer H 1996 Prenatal effects of betamethasoneL-carnitine combinations on fetal rat lung. J Perinat Med 24:591-599

15. Lohninger A, Krieglsteiner HP, Hajos F, Stangl H, Marz R 1996 Effects of prenatal treatment with betamethasone, L-carnitine, or betamethasone-L-carnitine combinations on the phosphatidylcholine content and composition of the foetal and maternal rat lung. Eur J Clin Chem Clin Biochem 34:387-391

16. Ramsay RR, Gandour RD, van der Leij FR 2001 Molecular enzymology of carnitine transfer and transport. Biochim Biophys Acta 1546:21-43

17. Calvani M, Reda E, Arrigoni-Martelli E 2000 Regulation by carnitine of myocardial fatty acid and carbohydrate metabolism under normal and pathological conditions. Basic Res Cardiol 95:75-83

18. Peluso G, Barbarisi A, Savica V, Reda E, Nicolai R, Benatti P, Calvani M 2000 Carnitine: an osmolyte that plays a metabolic role. J Cell Biochem 80:1-10

19. Alesci S, De Martino MU, Kino T, Ilias I 2004 L-carnitine is a modulator of the glucocorticoid receptor alpha. Ann N Y Acad Sci 1024:147-152

20. Alesci S, De Martino MU, Mirani M, Benvenga S, Trimarchi F, Kino T, Chrousos GP 2003 L-carnitine: a nutritional modulator of glucocorticoid receptor functions. FASEB J 17:1553-1555

21. Manoli I, De Martino MU, Kino T, Alesci S 2004 Modulatory effects of L-carnitine on glucocorticoid receptor activity. Ann N Y Acad Sci 1033:147-157

22. Bourgeois S, Pfahl M, Baulieu EE 1984 DNA binding properties of glucocorticosteroid receptors bound to the steroid antagonist RU-486. EMBO J 3:751-755

23. Lohninger A, Laschan C, Auer B, Linhart L, Salzer H 1996 [Animal experiment and clinical studies of the significance of carnitine for energy metabolism in pregnant patients and the fetus during the pre- and perinatal period]. Wien Klin Wochenschr 108:33-39

24. Liu Y, Havinga R, van der Leij FR, Boverhof R, Sauer PJ, Kuipers F, Stellaard F 2008 Dexamethasone exposure of neonatal rats modulates biliary lipid secretion and hepatic expression of genes controlling bile acid metabolism in adulthood without interfering with primary bile acid kinetics. Pediatr Res 63:375-381

25. Waylan AT, Kayser JP, Gnad DP, Higgins JJ, Starkey JD, Sissom EK, Woodworth JC, Johnson BJ 2005 Effects of L-carnitine on fetal growth and the IGF system in pigs. J Anim Sci 83:1824-1831

26. Smink JJ, Koedam JA, Koster JG, Buul-Offers SC 2002 Dexamethasone-induced growth inhibition of porcine growth plate chondrocytes is accompanied by changes in levels of IGF axis components. J Endocrinol 174:343-352

27. Price WA, Stiles AD, Moats-Staats BM, D'Ercole AJ 1992 Gene expression of insulin-like growth factors (IGFs), the type 1 IGF receptor, and IGF-binding proteins in dexamethasone-induced fetal growth retardation. Endocrinology 130:1424-1432

28. Markowska AL, Ingram DK, Barnes CA, Spangler EL, Lemken VJ, Kametani H, Yee W, Olton DS 1990 Acetyl-1-carnitine. 1: effects on mortality, pathology and sensory-motor performance in aging rats. Neurobiol Aging 11:491-498

29. Ames BN, Liu J 2004 Delaying the mitochondrial decay of aging with acetylcarnitine. Ann N Y Acad Sci 1033:108-116

30. Kira Y, Nishikawa M, Ochi A, Sato E, Inoue M 2006 L-carnitine suppresses the onset of neuromuscular degeneration and increases the life span of mice with familial amyotrophic lateral sclerosis. Brain Res 1070:206-214 
31. Kamitsuka MD, Peloquin D 1991 Renal calcification after dexamethasone in infants with bronchopulmonary dysplasia. Lancet 337:626

32. Blumenthal I 1991 The incidence of renal calcification in preterm infants. Arch Dis Child 66:1102

33. Cranefield DJ, Odd DE, Harding JE, Teele RL 2004 High incidence of nephrocalcinosis in extremely preterm infants treated with dexamethasone. Pediatr Radiol 34:138-142

34. Celsi G, Kistner A, Aizman R, Eklof AC, Ceccatelli S, de Santiago A, Jacobson SH 1998 Prenatal dexamethasone causes oligonephronia, sodium retention, and higher blood pressure in the offspring. Pediatr Res 44:317-322

35. Martins JP, Monteiro JC, Paixao AD 2003 Renal function in adult rats subjected to prenatal dexamethasone. Clin Exp Pharmacol Physiol 30:32-37

36. de Borst MH, van Timmeren MM, Vaidya VS, de Boer RA, van Dalen MB, Kramer AB, Schuurs TA, Bonventre JV, Navis G, van Goor H 2007 Induction of kidney injury molecule-1 in homozygous Ren2 rats is attenuated by blockade of the renin-angiotensin system or p38 MAP kinase. Am J Physiol Renal Physiol 292:F313-F320

37. Chang B, Nishikawa M, Sato E, Utsumi K, Inoue M 2002 L-Carnitine inhibits cisplatin-induced injury of the kidney and small intestine. Arch Biochem Biophys 405:55-64
38. Kopple JD, Ding H, Letoha A, Ivanyi B, Qing DP, Dux L, Wang HY, Sonkodi S 2002 L-Carnitine ameliorates gentamicin-induced renal injury in rats. Nephrol Dial Transplant 17:2122-2131

39. de Vries WB, van den Borne P, Goldschmeding R, de Weger RA, Bal MP, van Bel F, van Oosterhout MF 2010 Neonatal dexamethasone treatment in the rat leads to kidney damage in adulthood. Pediatr Res 67:72-76

40. Price N, van der Leij F, Jackson V, Corstorphine C, Thomson R, Sorensen A, Zammit V 2002 A novel brain-expressed protein related to carnitine palmitoyltransferase I. Genomics 80:433-442

41. Schreurs M, Kuipers F, van der Leij FR 2010 Regulatory enzymes of mitochondrial beta-oxidation as targets for treatment of the metabolic syndrome. Obes Rev 11:380-388

42. Wolfgang MJ, Kurama T, Dai Y, Suwa A, Asaumi M, Matsumoto S, Cha SH, Shimokawa T, Lane MD 2006 The brain-specific carnitine palmitoyltransferase-1c regulates energy homeostasis. Proc Natl Acad Sci U S A 103:7282-7287

43. López M, Lage R, Saha AK, Pérez-Tilve D, Vázquez MJ, Varela L, SangiaoAlvarellos S, Tovar S, Raghay K, Rodríguez-Cuenca S, Deoliveira RM, Castañeda T, Datta R, Dong JZ, Culler M, Sleeman MW, Alvarez CV, Gallego R, Lelliott CJ, Carling D, Tschöp MH, Diéguez C, Vidal-Puig A 2008 Hypothalamic fatty acid metabolism mediates the orexigenic action of ghrelin. Cell Metab 7:389-399 